\title{
SPACEBORNE QUANTITATIVE ASSESSMENT OF PRIMARY PRODUCTION VARIATIONS IN THE ARCTIC OCEAN OVER THE PREVIOUS DECADE
}

\author{
D. Pozdnyakov ${ }^{\mathrm{a}, \mathrm{b}^{*}}$, D. Petrenko ${ }^{\mathrm{a}}$ \\ ${ }^{a}$ Nansen International Environmental and Remote Sensing Centre (NIERSC), Saint-Petersburg, 199034, Russia - \\ dmitry.pozdnmysakov@niersc.spb.ru \\ ${ }^{\mathrm{b}}$ Nansen Environmental and Remote Sensing Centre (NERSC), Bergen, 5075, Norway- dmitry.petrenko@niersc.spb.ru
}

KEY WORDS: Arctic Ocean, Primary Production, Bio-optical Retrieval Algorithms, PP Decadal Trends, Projections

\begin{abstract}
:
Spaceborne one month averaged data, predominantly from the Sea-viewing Wide Field-of-view Sensor (SeaWiFS) and partly from the Moderate Resolution Imaging Spectroradiometer (MODIS), were used to investigate changes in primary production (PP) by phytoplankton in the Arctic Ocean from 1998 till 2010. Several PP retrieval algorithms were tested against the collected in situ data, and it was shown that the algorithm by Behrenfeld and Falkowski gave the best results (with the coefficient of correlation, $r$ equal to 0.8 and 0.75 , respectively, for the pelagic and shelf zones. Based on the performed test, the Behrenfeld and Falkowski algorithm was further applied for determining both the annual PP in the Arctic and the PP trend over the aforementioned time period. The results of our analysis indicate that PP in the Arctic has increased by $\sim 15.9 \%$ over 13 years. This finding, as well as the absolute annual values of PP remotely quantified in the present study, is at odds with analogous numerical assessments by other workers. These disagreements are thought to be due to differences in the applied methodologies of satellite data processing, such as cloud masking and determination of phytoplankton concentration within $(i)$ overcast areas, and (ii) areas of massive growth of coccolithophore algae, as well as (iii) in the shelf zone prone to a significant influence of land and river runoff. Hindcast (a decadal long) and forecast projections of PP

variations are performed.
\end{abstract}

\section{INTRODUCTION}

It is presently a commonly shared opinion that, as a result of climate change, there is a greater degree of warming at high latitudes than at lower altitudes, which is predicted to get worse over the twenty-first century.

The ongoing and projected climate change in the Arctic is accompanied by a host of consequences of both physical and biological nature.

The biological implications encompass inter alia changes in nutrient availability and algal cell metabolism rates, shifts of phytoplankton community composition, and enhancement of primary productivity in the water column.

In turn, variations in the primary production (PP) rate in the Arctic affect the carbon cycle in the atmosphere-ocean system and ultimately lead, through feedback mechanisms, to climate change at the global scale.

Under warmer conditions, the amount of carbon sequestered by the Arctic Ocean can be expected to increase. Thus, an adequate estimation of this increase is a task of significant importance.

The size of the Arctic Ocean and the phytoplankton spatial and temporal variability means that to observe the phytoplankton dynamics, remote sensing is necessitated. Special PP retrieval models/algorithms are required to attain this goal.

The PP algorithms developed to date are fairly numerous (for refs. see Petrenko et al., 2013). Among the PP models cited most frequently in connection with their applicability specifically to the northern Atlantic waters are the algorithms suggested by Marra, et al. (2003), Behrenfeld and Falkowski (1997), Behrenfeld et al. (2005), and Pabi, et al. (2008). However, of these four, only the Pabi, van Dijken, and Arrigo model has been tested for the Arctic Ocean .

The few publications that have appeared so far demonstrate large uncertainties in remote determination of the actual

\footnotetext{
Corresponding author
}

tendency in PP decadal variations in the Arctic (Pabi, et al., 2008; Babin and Belager, 2011; Arrigo and van Dijken, 2011).

Presumably, this is due to a variety of factors, possibly including the inadequacy of algorithms designed for PP retrieval from space.

Unfortunately, the code for the Pabi, van Dijken, and Arrigo model was not available to us, and in the present study we analysed the efficiency of only three algorithms (suggested by Behrenfeld and Falkowski (1997), Behrenfeld et al. (2005), and Marra, et al (2003)), making use of data from the Sea-viewing Wide Field-of-view Sensor (SeaWiFS) (and, marginally, from the Moderate Resolution Imaging Spectroradiometer (MODIS) for those months when the SeaWiFS sensor did not work) in conjunction with a unique database of PP in situ determinations in the Arctic collected by us. However, we compared our results (PP values and trends) with the results published by Pabi et al. (2008) and Arrigo and van Dijken (2008, 2011).

\section{COLLECTED IN SITU, MODEL SIMULATION, AND SPACEBORNE DATABASES}

For reasons of simplicity, we assumed in the present study that the Arctic Ocean is the area lying north of $65^{\circ} \mathrm{N}$ beyond the Polar Circle (see, e.g. Pabi et al., 2008).

\subsection{In situ data}

The compiled gridded shipborne database covers the time period of 1958-2005 and incorporates gridded PP determinations (ca 9000).

When selecting the in situ data eligible for algorithm validation, the major criteria were the closeness of the chlorophyll maximum to the water surface, the shortest possible time difference between the in situ measurement and the ocean colour sensor overflight, and the location of the sampling station within 
a $16 \mathrm{~km}$ radius area around the pixel for which the comparison was performed.

In addition to the PP at surface in situ data, data on PP profiles were collected as well as a wealth of contemporaneous in situ data on a number of so-called associated, such as phytoplankton chlorophyll concentration (chl), sea surface temperature (SST), cloudiness level, incident and downward photosynthetically active radiation (PAR); PAR diffuse attenuation coefficient; euphotic depth; remote-sensing reflectance above the water surface $\left(R_{\mathrm{rs}}\right)$; mixed layer depth (MLD); and water temperature and salinity profile, etc..

The collected in situ data cover not only the pelagic areas (such as the north Atlantic ice-free surface, the Russian Sector of the Central Arctic, and the Canadian Basin) but also the peripheral seas: Greenland, Barents, White, Pechora, Kara, Laptev, Chukchi, and Beaufort.

\subsection{Spaceborne data}

2.2.1 Ocean colour data. The following most recently reprocessed SeaWiFS and MODIS-Aqua monthly binned ocean colour gridded data set was used: the OceanColor MEASURES Project data (Reprocessing R20010). The latter (further referred to as MEASURES data) are obtained with the GSM retrieval algorithm and a special procedure of partial removal of cloudiness (http://adsabs.harvard.edu/abs/

2008AGUFMIN51B1156M). The collected set of data is level 3 monthly averaged retrieval results at a spatial resolution of 4 $\mathrm{km}$.

SeaWiFS and MODIS-Aqua data (Level 3) were processed with the Levenberg-Marquardt technique-based BOREALI algorithm (Korosov et al. 2009b) for processing ocean colour data from $(a)$ the Arctic shelf zone encompassing the Arctic seas and (b) Emiliania huxleyi bloom areas.

Apart from the phytoplankton chlorophyll $(\mathrm{chl})$, ocean colour data routinely encompass the values of $\operatorname{PAR}, \operatorname{Rrs}(\lambda)$, spectral coefficient of diffuse attenuation at the wavelength $\lambda=490 \mathrm{~nm}$, $K_{\mathrm{d}}(490)$, and coefficient of $\mathrm{chl}$ absorption $\left(a_{\mathrm{chl}}\right)$, and coefficient of backscattering $\left(b_{b c h l}\right)$ at the wavelength $\lambda=490 \mathrm{~nm}$.

SeaWiFS and MODIS data cover the time periods of, respectively, 1998-2010 and 2002-2010.

\subsubsection{Sea-surface temperature, ice-free surface, and} cloudiness. These data were obtained from

$\mathrm{SSM} / \mathrm{I}$ sequential sensors, the longest time series is on sea ice (32 years). The time series (24 years, until 2009) on SST is from sequential sensors, the Advanced Very High Resolution Radiometer (AVHRR), and partly ( 8 years) from MODIS. The data from the sequential sensors posted on the sites are harmonized by respective agencies with due account of the specific radiometric parameters inherent in each successive sensor.

The employed time series of data on cloudiness starts from 1998 - the year of the inception of SeaWiFS steady sounding of oceans.

The extension of the AVHRR SST data series beyond 2009 was performed using respective MODIS data with a preliminary verification of a strict correspondence of both sets of data for the preceding period of 2002-2009.

To avoid the optical interference arising at cloud edges (for references, see Robinson 2004), and hence the ensuing inaccuracies in our quantitative determinations, we excluded a two-pixel-wide water strip bordering the cloud-edge projection on the water surface in all assessments of $c h l$ concentrations and eventually the values of PP.

\section{METHODOLOGY}

The entire area of the Arctic Ocean can be partitioned into pelagic and shelf zones based on morphometric and geomorphologic parameters such as bed slope and its gradient. Since pelagic and shelf zones are known to differ essentially in terms of water optical properties, the algorithms for the retrieval of chl should be specialized for both types of area). We also used a segmental division into eight sectors incorporating individual Arctic seas: I Greenland Sea, II Barents Sea, III Kara Sea, IV Laptev Sea, V East Siberian Sea, VI Chukchi Sea, VII Beaufort Sea, VIII Baffin Bay.

\subsection{PP retrieval algorithm}

A preliminary investigation conducted by us using the collected PP in situ data has shown that the Behrenfeld and Falkowski (1997 yielded the best retrieval results.

3.1.2. Behrenfeld and Falkowski (1997) algorithm is a vertically generalized/depth-integrated production model (VGPM). (PP $)_{\mathrm{eu}}$ in the entire euphotic zone, $z_{\mathrm{eu}}$ is modelled as follows:

$$
(\mathrm{PP})_{\mathrm{eu}}=0.66125 P^{B}{ }_{\mathrm{opt}}\left[E \mathrm{o} /(E \mathrm{o}+4.1) z_{\mathrm{eu}}(\operatorname{chl})_{\mathrm{opt}} L \mathrm{D}\right]
$$

where 0.66125 is a scaling factor, $P^{B}{ }_{\text {opt }}$ is the assimilation efficiency and a function ofwater temperature (the word 'opt' representing 'optimal'): $3.27 \times 10^{-8} \times T^{7}+3.4132 \times 10-6 \times T^{6}+$ $1.348 \times 10^{-4} \times T^{5}+2.462 \times 10^{-3} \times T^{4}-0.0205 \times T^{3}+0.0617 T^{2}+$ $0.2749 T+1.2956\left(\mathrm{mg} \mathrm{C} \mathrm{mg}\left(\mathrm{chl}^{-1}\right)^{-1}\right.$ hour $\left.^{-1}\right) ; E_{\mathrm{o}}(\lambda)$ is the incident PAR irradiance, $z_{\text {eu }}=\ln (0.01) / K_{\mathrm{d}}(490)(\mathrm{m}), K_{\mathrm{d}}$ is the diffuse irradiance attenuation coefficient at $\lambda=490 \mathrm{~nm}\left(\mathrm{~m}^{-1}\right)$, day length $(L D)$ (hour).

$c h l_{\text {opt }}$ is found to correlate strongly with the spaceborne value of $c h l$, $\operatorname{chl}_{\text {sat }}(r=0.96)$ (the subscript 'sat' representing 'satellite'), and, owing to the near-surface location of $P^{B}{ }_{\text {opt }}\left(\xi_{\text {opt }}<1.3\right)$, it is assumed that $c h l_{\text {opt }}=c h l_{\text {sat }}$.

Thus, the spaceborne input variables are $c h l$ at the depth nearest to the surface, incident PAR irradiance, $E_{0}(\lambda)$, and sea-surface temperature, SST.

Importantly, the above relationship between $P^{B}$ opt and water temperature holds for SST ranging from $-1^{\circ} \mathrm{C}$ to $+29^{\circ} \mathrm{C}$.

\subsection{Phytoplankton $c h l$ retrieval algorithms}

According to the adopted repartitioning of the arctic waters, we applied differentially the phytoplankton $c h l$ retrieval algorithms.

\subsubsection{Shelf zone}

3.2.1.1. BOREALI algorithm. Owing to a significant influence of land and river run-off, coastal waters are generally optically complex (as compared to pelagic waters) as a result of the presence, in addition to phytoplankton, of suspended minerals $(\mathrm{sm})$ and the coloured fraction of dissolved organic matter (dom). The NASA algorithms operate better in offcoastal, optically simple waters, coined case I waters (Sathyendranath 2000). To circumvent this problem, we performed the retrieval of $\mathrm{chl}$ concentrations (simultaneously along with the retrieval of concentrations of $\mathrm{sm}$ and coloured dom) from level 2 of the NASA SeaWiFS and MODIS-Aqua data, making use of the BOREALI algorithm developed specifically for coastal/optically complex waters (the so-called case II waters) experiencing a significant impact of land and river run-off (Korosov et al., 2009a). Parenthetically, it should be noted that, generally, the BOREALI algorithm can also be applied to off-coastal/optically 
clear waters but it is not rational if the NASA/ESA standard chlretrieval algorithms (simpler and faster to use) yield equally good results.

In the present research we applied the BOREALI algorithm not only to the shelf zone of the Arctic Ocean, assuming that it subsumes under the category of optically complex waters (this assumption is based on our previous studies (Korosov et al., 2011)), but also the areas of blooms of a coccolithophore, $E$. huxleyi.

The BOREALI algorithm relies on analysis of the observed/retrieved spectral subsurface remote-sensing reflectance, $R_{r s w}(\lambda, C)$, which is the up-welling spectral radiance just beneath the water-air interface normalized to the downwelling spectral irradiance at the same level. Through varying the concentration vector $\boldsymbol{C}=[\mathrm{chl}, \mathrm{sm}, \mathrm{dom}]$ and minimization at each wavelength of the function $f(\boldsymbol{C})$ of squares of residuals of the difference between the observed/retrieved and simulated values of $R_{r s w}$, the absolute minimum can be found with the Levenberg-Marquardt finite difference algorithm (Press et al., 1992).

Simulation of $R_{\mathrm{rsw}}$ requires the hydro-optical model inherent in the aforementioned waters of the Arctic Ocean. For optically complex waters beyond the coccolithophore blooms, the hydrooptical model suggested for oligo- and mesotrophic waters by Kondratyev et al. (1990) has successfully been applied to Arctic waters ( Korosov et al., 2011).

The necessity of application of the BOREALI algorithm in each pixel has been determined based on the spectral curvature of $R_{\mathrm{r}}$ $(\lambda)$, reflecting the belonging of target waters either to case I or case II waters (see, e.g. Bukata et al., 1995).

\subsection{Pelagic zone}

For the ice-free pelagic region of the Arctic Ocean, we employed The Garver-Siegel-Maritorena semi-analytical (SA) ocean colour algorithm (GSM algorithm) that retrieves simultaneously the phytoplankton chl concentration, the absorption coefficient for dissolved and detrital materials $\left[a_{\mathrm{cdm}}(443)\right]$, and the particulate backscatter coefficient $\left[b_{\mathrm{bp}}(443)\right]$ (Maritorena et al., 2002).

For processing the areas of $E$. huxleyi a modified BOREALI algorithm proves to be useful (Morozov et al., 2012). In the modified BOREALI algorithm, we used a hydro-optical model accounting for the optical impact of (1) the spectral optical properties of E. huxleyi cells as well as coccoliths, (2) diatoms, and (3) water per se. The hydro-optical model has been composed making use of the required data reported in the literature (for refs. see Petrenko et al., 2013).

Balch et al. (2005) have shown that the optical properties of $E$. huxleyi cells are geographically pretty invariable and could be globally applied.

First, the L3 spaceborne data were processed with the modified BOREALI algorithm to yield the summed concentration of $\mathrm{ch}$ contained in both E. huxleyi and diatoms coexisting within the bloom area. Then the resultant $c h l$ was used as input for the tested PP algorithms.

\section{3. ALGORITHM FOR THE RETRIEVAL OF SST}

The SST retrieval algorithms (the so-called window-split algorithms) employ the difference between the satelliteobserved water surface apparent or else brightness temperature $T i$, determined in several spectral channels. The NASA algorithm is a four-term expression whose details can be found at http://yyy.rsmas.miami.
edu/groups/rrsl/pathfinder/Algorithm/algo_index.html\#algopathsst and http://modis.gsfc.nasa.gov/data/atbd/atbd_mod25.

\subsection{ICE COVER AND FILLING OF CLOUD- MASKED PIXELS}

Data on sea ice concentrations are generated from brightness temperature data. They are derived from the Nimbus-7 Scanning Multichannel Microwave Radiometer (SMMR); the Defense Meteorological Satellite Program (DMSP) -F8, -F11, and -F13 Special Sensor Microwave/Imagers (SSM/Is); and the DMSPF17 Special Sensor Microwave Imager/Sounder (SSMIS), include quantifications of the fraction, or percentage, of ocean area covered by sea ice.

The Arctic Basin has been divided into sectors, first, according to latitudinal principles, and second, on the longitudinal basis. At the beginning, the pelagic tracts of the Basin were split into two circular areas with the limits for the shelf zone: $<72^{\circ} \mathrm{N}$ and the ice edge $>72^{\circ} \mathrm{N}$ : our in situ and spaceborne data explicitly indicate that this latitude is a conditional abutment between more and less productive pelagic waters. Further, these two circular areas were split into four sectors: $42^{\circ} \mathrm{W}-50^{\circ} \mathrm{E}, 50^{\circ} \mathrm{E}-$ $120^{\circ} \mathrm{E}, 120^{\circ} \mathrm{E}-130^{\circ} \mathrm{W}$, and $130^{\circ} \mathrm{W}-42^{\circ} \mathrm{W}$

For each cloud-covered pelagic area within the above circular regions and sector segments in a given year $Y$, the coefficient of proportionality was calculated for each month of the phytoplankton vegetation period as a ratio of the mean PP over each individual area in question in a previous year $Y-n$ when the area is cloud-free to the mean PP over the respective latitudinal sector across the Arctic Basin in the same year, $Y-n$. When cloudiness conditions permitted, the above monthly coefficients of proportionality were averaged over several years. To account for cloud attenuation of the incident radiation, we estimated PP along the outer boundary of the cloudy area, and also when there were clearances with the cloudy area. Statistically, we determined that due to the cloud masking, the actual PP on average is less by a factor of $\sim 0.83$ (root mean square difference (RMSD) $=\sim 0.03$ ). This was taken into account when definitively determining the coefficients of proportionality described above. Tables for each zone have been calculated. For the most ice-free time in the Arctic, the average coefficient of proportionality for the pelagic zone proved to be $0.76($ RMSD $=0.14)$. The average value of the coefficient is $0.72($ RMSD $=0.13)$. The standard deviations proved to be rather low, which is an indication that the values of the coefficients are rather stable. Thus, variations in the mean value of the proportionality coefficient in each month within the determined standard deviations do not alter the quantitative estimation of PP by more than $\sim 1.6 \%$.

For the determination of the counterpart coefficients of proportionality for the marine shelf waters, the above segmentation has also been employed. Analysing the downloaded multi-year spaceborne information, we found that the shelf zone in the Arctic is characterized by the presence of inter-annually stable areas of high productivity persisting during all vegetation months. Therefore, the coefficients of proportionality discussed above had to be calculated separately for high-productivity areas (if the cloudiness occurred over such areas) and for the rest of the shelf waters when the cloudiness was located within them.

Each year, almost invariably, highly productive areas (HPAs) are only partially masked by cloudiness, but the location of the masked area varies inter- and intra-annually. For each

cloud-covered spot (let us call it $\omega_{i}$ ) within a HPA that occurred during the period of observations, the coefficient $\zeta$ was calculated for each year and month as follows. We find a 
neighbouring year when $\omega i$ is cloud-free, determine the value of $\mathrm{PP}(\mathrm{PP})_{1}$ for it, and divide by the mean value $(\mathrm{PP})_{2}$ in the rest of the cloud-free part of the HPA in a given year/month. We run this procedure for all years and seasons of our observations. Further, for each month, we determine the statistical average value of the coefficient of proportionality $\xi$ for all years of observation and then apply it to calculate PP in cloudy areas in each year and month

In low productive areas (LPAs) of the shelf zone, which are spatially pretty homogeneous, the PP values of cloud-masked areas were taken as the mean PP values of LPA for the given year and month.

Accounting for the impact of incident irradiance due to cloudiness was performed analogously as was done for the pelagic zone (see above). Statistically, it was determined that, due to the cloud masking, the actual PP in these waters on average is less by a factor of $\sim 0.82$ (RMSD $=0.05$ ).

\subsection{COMPATIBILITY OF SEAWIFS AND MODIS DATA}

There were hitches in SeaWiFS operation in July and September in 2008, and September in both 2009 and 2010. To fill the gaps, we used MODIS-Aqua data for the above months. Our comparisons indicate that MODIS somewhat overestimates chl as compared with the SeaWiFS counter-values, especially at chl $>1.4 \mu \mathrm{g}^{-1}$. Incidentally, the same result been obtained by for the Bay of Biscay (Morozov et al., 2012). Our analysis has shown for 2002-2010 that for about $90 \%$ of the pixels compared, the ratio between $c h l_{\text {SEAWIFS }}$ and $c h l_{\text {MODIS }}$ is 0.81 , i.e. $c h l_{\text {SEAWIFS }}=0.81 c h l_{\text {MODIS }}(\mathrm{RMSD}=0.11)$. We also checked this result employing normalized water leaving radiance $(n L w)$ based analysis, and found no bias. This fact was taken into account (through the above regression relationship) when developing chl time series as inputs into PP algorithms.

\section{RESULTS}

\subsection{Investigation of multi-year PP trends in the ice-free arctic basin}

4.1.1. Pelagic ice-free zone. Table 1 the revealed trend in annual PP: starting from 1998, annual PP in the ice-free pelagic zone of the Arctic has been increasing at a rate of $1.1 \%$ per year, so that according to our estimations, PP in this zone increased by $14.5 \%$ over 13 years. The absolute values of PP varied during this period within the interval extending from $\sim 380 \mathrm{Tg} \mathrm{C}$ until $\sim 510 \mathrm{Tg}$ C. The mean PP per unit area in this zone over the vegetation period between 1998 and 2010 is assessed at $89 \mathrm{mg} \mathrm{C}$ $\mathrm{m}^{-2}$ day $^{-1}$. The same Table illustrates the estimated respective trends in the variables that are believed to be consequential for the established PP dynamics.

Through comparing the retrieved data on phytoplankton productivity, pp (in $\mathrm{mg} \mathrm{C} \mathrm{m}^{-2}$ day $^{-1}$ ) with the respective gridded in situ data, the mean square deviation for satellite pp data was quantified and considered as the error of pp retrievals, $\delta p p$. Further, PP (Tg C day ${ }^{-1}$ ) was calculated for each pixel: (PP) $=(\mathrm{pp})_{\text {pixel }} \sigma$, where $(\mathrm{pp})_{\text {pixel }}$ is the phytoplankton productivity per pixel (in $\mathrm{m}^{2}$ ), and $\sigma$ is the pixel surface (in $\mathrm{m}$ ).

The PP retrieval error was calculated as $\delta(\mathrm{PP})_{\text {pixel }}=\delta p p \sigma$.

The value of PP for the pelagic zone is a result of summation of all (PP) $)_{\text {pixel }}=\Sigma \mathrm{PP}_{\text {pixel. }}$.

The resultant error for the pelagic zone was quantified analogously: $\delta(\mathrm{PP})=\Sigma \delta(\mathrm{PP})_{\text {pixel }}$.
A similar procedure was exploited for determining PP and $\delta(\mathrm{PP})$ within the shelf zone and the entire Arctic Basin. The respective values of $\delta(\mathrm{PP})$ were then used to plot the error bars.

As a result, the PP error proved to be $24 \%, 26 \%$, and $25 \%$ for the pelagic, shelf zones, and the entire Arctic, respectively.

\begin{tabular}{|c|c|c|}
\hline Variable & Trend (\%) & $\begin{array}{c}\text { Statistical } \\
\text { significance }\end{array}$ \\
\hline PP & +14.5 & 98 \\
Ice-free area & +18 & 99 \\
chl & +17 & 99 \\
PAR & -2 & 93 \\
SST & +22 & 99 \\
\hline
\end{tabular}

Table 1. Pelagic zone of the ice-free Arctic Basin: 13- year trends in the dynamics of annual PP, ice cover, chl, PAR, and SST. Time period: 1998-2010.

4.1.2. Ice-free shelf zone. Table 2 illustrates the revealed trend in, PP: starting from 1998, PP in the ice-free shelf zone of the Arctic has been increasing at a rate of $1.3 \%$ per year. So, according to our estimations, PP in this zone increased by $17.4 \%$ over 13 years. The absolute values of PP varied during this period within the interval extending from $\sim 360$ until $\sim 500 \mathrm{Tg} \mathrm{C}$ year-1. The mean daily PP per unit area in this zone over the vegetation period between 1998 and 2010 is assessed at $93 \mathrm{mg} \mathrm{C}$ $\mathrm{m}^{-2}$ day $^{-1}$. Table 2 also shows the estimated respective trends in the variables that are believed to be consequential for the established PP dynamics.

We found that the maximum daily PP per unit area in the icefree shelf zone occurs in May. Its mean value for this month over 1998-2010 is about $105 \mathrm{~g} \mathrm{C} \mathrm{m}^{-2} \mathrm{day}^{-1}$. PP has been increasing to eventually reach in 2010 a value of $\sim 113 \mathrm{~g} \mathrm{C} \mathrm{m}^{-2}$ day ${ }^{-1}$ against $\sim 104 \mathrm{~g} \mathrm{C} \mathrm{m}^{-2}$ day $^{-1}$ in 1998 , which implies a trend of $8.1 \%$ per 13 years.

\begin{tabular}{|c|c|c|}
\hline Variable & Trend (\%) & $\begin{array}{c}\text { Statistical } \\
\text { significance }\end{array}$ \\
\hline PP & +17.4 & 98 \\
Ice-free area & +58 & 99 \\
chl & +13 & 99 \\
PAR & -1 & 93 \\
SST & +19 & 99 \\
\hline
\end{tabular}

Table2. Shelf zone of the ice-free Arctic Basin: 13year trends in the dynamics of annual PP, ice cover, chl, PAR, and SST. Time period: 1998-2010.

Comparing the PP dynamics in pelagic and shelf zones, at the early stages of the vegetation period, the monthly production in the pelagic zone nearly equals that in the shelf zone. But further on, the PP maximum shifts from May (registered for the shelf zone) to June for the pelagic zone. This is a quite expected result as SST (highly determining the phytoplankton productivity) in the shelf zone increases faster than it does in the deep, initially colder, pelagic waters. However, in July, PP in both zones becomes closely comparable. During the period AugustOctober, the water in the shelf zone remains warmer than it is in the pelagic zone, thus determining a less steep decrease in PP compared to the pelagic waters.

For the pelagic zone, the (PP) $)_{\max }$ mean value over 1998-2010 for June is about $130 \mathrm{gC} \mathrm{m}^{-2} \mathrm{day}^{-1}$. In the case of the shelf zone, the respective value is less than $110 \mathrm{~g} \mathrm{C} \mathrm{m}^{-2} \mathrm{day}^{-1}$. 
4.1.3 Entire ice-free Arctic Basin. Summation of our estimations of PP in the ice-free pelagic and shelf zone showed that in absolute values, PP varied within the range from $770 \mathrm{Tg}$ $\mathrm{C}$ year $^{-1}$ to $! 980 \mathrm{Tg} \mathrm{C}$ year $^{-1}$. Over 13 years, PP has been increasing at a rate of $15.9 \%$ or about $1.2 \%$ per year (statistical significance $=99 \%$ ). Over the vegetation period, the mean PP production per unit area in the entire ice-free Arctic Basin between 1998 and 2010 is assessed at $91 \mathrm{mg} \mathrm{C} \mathrm{m}^{-2}$ day $^{-1}$.

\subsubsection{Interannual variations and linear trends in $P P$ over}

the sectors encompassing the Arctic seas.The revealed temporal variations in annual PP for the Arctic sectors (conditionally named after the respective seas they incorporate) exhibit significant individual features (Table 3) which is reflected in the respective values of trends.

As Table 3 illustrates, the greatest share in the total annual PP over the ice-free Arctic Basin belongs to two sectors, viz. the Barents and Greenland sectors ( $35 \%$ and $30 \%$, respectively). The least productive marine environments in the Arctic are the East Siberian and Chukchi sectors.

In summary, the annual PP of the Arctic seas either equalled or, more often, prevailed over the annual PP in the pelagic zone, with the exception of 2005 and 2007.

Data in Table 3allows to numerically compare the quantified PP data for each sector. Here the differences for most seas are significant. The causal reasons of this dissimilitude is discussed below in the final section.

\begin{tabular}{|c|c|c|}
\hline \multirow{2}{*}{ Arctic sector } & \multicolumn{2}{|c|}{ Trend (\%) } \\
\cline { 2 - 3 } & Over 1998-2010 & Per year \\
\hline Kara Sea & 22.4 & 1.7 \\
Laptev Sea & 54. & 4.2 \\
Greenlan Sea & -13.6 & -1 \\
East Siberian & 112.7 & 8.6 \\
Sea & & \\
Chukchi Sea & 57.2 & 4.4 \\
Beaufort Sea & 14.7 & 1.1 \\
Barents Sea & 19.7 & 1.4 \\
Baffin Sea & 9.9 & 0.8 \\
\hline
\end{tabular}

Table 3. Trends in annual PP for the eight individual Arctic sectors conditionally named after the respective seas.

\section{ASSESSMENT OF THE PHYTOPLANKTON PRODUCTIVITY TREND IN THE ICE-FREE ARCTIC BASIN PRIOR TO 1998}

As stated above, the database collected by us contains PP shipborne data starting mainly in 1977 . These historical data were yet insufficient to confidently determine the PP trend between 1977 and 1998 with a statistically significant coefficient of correlation ( $r$ was found at 0.2 ) because the spatial distribution of water sampling stations and the number of shipborne measurements were very significantly inhomogeneous. However, to determine the variations of PP during the 'pre-SeaWiFS' period (from 1998 backwards), we followed the methodology used by Arrigo and van Dijken (2011). The dependence of PP on ice cover is convenient to study through the summer minimum sea ice extent $(\boldsymbol{S})$, which is strongly correlated to total PP. We found that there is a nearly linear dependence of PP (determined by our methods from satellite data) on $\boldsymbol{S}$ for the satellite era, i.e. 1998-2010. $(r=0.51$, $p<0.001)$. In the next step, the variations of $\boldsymbol{S}$ were determined for the time period 1979-2010 using the microwave data. It turned out that around 1994-1995 the value of $\boldsymbol{S}$ started decreasing at a greater rate than earlier. Importantly, in both periods the temporal variations of $\boldsymbol{S}$ can be approximated by linear correlation expression.

Keeping in mind that the relationship between PP and $\boldsymbol{S}$ are found to be also linear, and having already established the PP trend between 1998 and 2010, it is possible to linearly extrapolate the PP trend from 1979 to 1954-1955, and then further till the intersection with the trend for the period 19992010.

This approach permitted us to tentatively quantify the rate of PP increase during the pre-SeaWiFS period. It proved to be $4.6 \%$. Thus, the above assessments indicate that the PP rate has been continuously (but not linearly) increasing during the last 31 years.

We also analysed the temporal variations of the phytoplankton productivity before 1998 and during 1998-2010. We addressed our in situ data obtained prior to 1997, analysing them in this regard. The collected in situ productivity data were transformed into monthly averaged values over June-August of the observation period. Based on the data thus obtained, the productivity trend was established for 1959-1997. It proved to be $+25.7 \%$. To confirm the validity of this assessment, we determined from the collected in situ data the phytoplankton productivity trend for the 'ocean colour era', i.e. for the period 1998-2005. It proved to be $+5 \%$. Further, the 'in situ' productivity trend was compared with the phytoplankton productivity trend determined using the Behrenfeld and Falkowski (1997) algorithm (with the application of the respective chl retrieval algorithms,see respective sections above). The 'spaceborne' productivity trend was found at $+6 \%$. We also determined the productivity trends separately for the pelagic and shelf zones. They proved to be $3.8 \%$ and $9.0 \%$. We believe that the above inconsistency between $+5 \%$ and $+6 \%$ should be attributed to the prevailing body of in situ measurements restricted to the shelf zone.

Summing up, it could be concluded that, according to the in situ data, the annual phytoplankton productivity in the Arctic has been growing at a rate of $0.69 \%, 0.67 \%$, and $0.71 \%$ during, respectively, the 1959-2005, 1959-1997, and 1998-2005 time intervals.

The annual rate of productivity determined from space is assessed at $0.86 \%$. Again, the difference between the in situ and spaceborne assessments of productivity for the period 1998 2005 resides in the fact that the prevailing body of in situ measurements were restricted to the shelf zone.

\section{DISCUSSION OF THE RESULTS}

The research performed has shown that the Behrenfeld and Falkowski (1997) PP algorithm assures reliable and consistent PP assessments from space, which was documented through comparisons with gridded in situ data

Owing to the high reliability of the obtained PP estimations, we can say that over a period longer than a decade, PP in the icefree Arctic has increased by $15.9 \%$. The major contribution to this increase came from the shelf seas where PP increased by $17.4 \%$ whereas in the pelagic zone PP increased only by $14.5 \%$ during the same time period (13 years). Our calculation results presented in Tables 1and 2 imply that the factors capable of impacting PP (the list of factors is certainly not exhaustive but includes those that satellite remote sensing can yield) varied during that period with trends being differently directed. Dramatic changes have occurred in ice cover, ice-free time period, SST, and $c h l$. Along with the aforementioned factors, the phytoplankton annual productivity continuous growth over the 
time period 1959-2005 established by us, there is also an important factor: the productivity rate increased over this period by about $\sim 32 \%$ (!) with the annual increments being about $0.7 \%$ (in situ data).

At the same time, during the period 1998-2005, PAR has only slightly decreased, and it was the time of a declining phase of North Atlantic Oscillation (NAO).

Most significantly, ice-free area and ice-free time period have increased in the Arctic seas whereas the increase in $\mathrm{chl}$ was comparable for both pelagic and shelf zones $(17 \%$ and $13 \%$, respectively). At the same time, PP has increased by $17.4 \%$ in the shelf zone, leaving behind, in this respect, the pelagic zone $(+14.5 \%)$. The reason why the $c h l$ increase in the shelf zone is less than that in the pelagic waters is thought to be an increased turbidity of shelf zone waters as a result of enhanced input of terrigenous suspended minerals and coloured dissolved organic matter (Korosov et al., 2011). However, the fact that chl has increased can be explained by the growing input of nutrients arising from climate-warming-driven intensification of river discharge (Hessen et al., 2010). At the same time, the increase in chl in the pelagic zone is probably due to increased water stratification produced by fresh water from melting ice cover (Timmermans et al., 2011), although some other factors such as phytoplankton community changes (due to, e.g. SST increase) might be at the base of the chl increase (Greene and Pershing, 2007).

The revealed trends are at odds with the data published by Pabi et al. (2008) $(+30 \%$ over $1998-2006$, i.e. 9 years $)$; Arrigo and van Dijken (2008) ( $+29 \%$ over $1998-2008$, i.e. 11 years); and Arrigo and van Dijken (2011) (+20\% over $1998-2009$, i.e. 12 years).

When referred to one and the same time period of 10 years (1998-2007), the values of the PP trends reported by the above authors are: Pabi et al. (2008), Arrigo and van Djken (2008) $+28 \%$; Babin and Belanger (2011); Arigo and van Dijken (2011) $+29 \%$; present study $+9.9 \%$.

The absolute values of PP over the entire ice-free Arctic assessed by us and Arrigo and van Dijken (2011) also differ very substantially.

The ice-free/open water areas determined by us and Arrigo and van Dijken (2011) are very close; also very close are the time periods of open water determined in both works.

If we compare PP interannual variations by Arrigo and van Dijken (2011) and our data provided the overcast open areas are not filled with the respective chl data then both the absolute values of and trends in PP become much closer: trends are $15.8 \%$ per 12 years and $18.4 \%$ per 13 years, the PP ranges are $\sim 450-600 \mathrm{Tg} \mathrm{C}$ year $^{-1}$ and 400-510 $\mathrm{Tg} \mathrm{C}^{-}$year $^{-1}$, reported, respectively, by Arrigo and van Dijken (2011) and us. This implies that filling the overcast open areas with $c h l$ data is a very essential factor: when ignored, it brings about a significant underestimation of PP in the Arctic.

At the same time our PP values (when overcast open areas are not filled with chl data) are steadily less (by about $30-70 \mathrm{Tg} \mathrm{C}$ year ${ }^{-1}$ ) than those reported by Arrigo and van Dijken (2011). This might reside in (1) the difference of the applied

PP algorithm, (2) ignoring of E. huxleyi blooms (within which the $c h l$ concentration is overestimated by the NASA standard algorithm applied by Arrigo and van Dijken (2011)),

and (3) the difference in partitioning of the Arctic Basin. Indeed, our delimitation of the pelagic and shelf zone is based on the drastic dissimilitude of the optical properties of these two types of waters. The OC3 algorithm applied by Arrigo and van Dijken (2011) to a sectorially divided water basin is known to be significantly inaccurate in the case of waters strongly influenced by land and river run-off (Bukata et al., 1995). At the same time, the BOREALI algorithm applied by us has been developed specifically for such waters.

Our estimations indicate that monthly mean PP per unit area has a tendency to increase: in the pelagic zone, during the last 13 years the respective trend for the month of maximum $\mathrm{PP} \mathrm{m}^{-} 2$ day $^{-1}$ (occurring in June) constituted $10.9 \%$. A similar situation is found for the shelf zone: the month of maximum PP per $\mathrm{m}^{2}$ (occurring in May); the trend constituted $8.1 \%$. These results are consistent with our finding of a steady growth of chl in both zones over the period 1998-2010 (Tables 1 and 2).

Obviously, the inferred enhancement of three important factors, viz. chl, the ice-free area, and the ice-free period duration (according to Arrigo and van Djiken (2011), sea ice retreated a total of 28 days earlier in 2009 than in 1998), largely explains the observed trends in PP in the Arctic.

Our assessments have shown that the highest increase in PP over the studied 13 years has occurred in the eight sectors that remained until 1998 the least productive ones: the trend constituted over $112 \%$ and $57 \%$, respectively, for the East Siberian and Chukchi sectors. In the sectors with a higher trophic status (Kara, Barents, Greenland, Beaufort, and Baffin sectors), the trend did not exceed $20 \%$. In terms of PP, the Laptev sector is in the middle between productive and oligotrophic Arctic sectors; however, its PP trend proved to be as high as $\sim 55 \%$. Schmid et al. (2006) characterize the Laptev Sea as 'one of the least understood regions of the world's oceans'.

Located over a shallow and broad shelf plateau, this sea is a recipient of a high influx of river water, sediments, and nutrients during summer, and long-lasting sea-ice cover from October to May. The ongoing climatic changes have brought about a significant reduction in ice cover and an appreciable increase in open water period (Arrigo and van Dijken, 2008). This is accompanied by a steadily increasing precipitation over the catchment of explicitly as well as the Lena River (Peterson et al. 2002). It could be conjectured that a combined action of the above factors brought about the above very steep increase in PP. At the same time, the Kara Sea seems to be subjected to very similar external forcing; however, the trend is far weaker. This implies the necessity of a more detailed and quantitative analysis of the driving mechanisms that resulted in the $\sim 50 \%$ trend in PP in the Laptev Sea/sector between 1998 and 2010.

The trend of $\sim 19.7 \%$ in PP in the Barents sector is certainly due to the appreciable increase in the ice-free area and duration of the ice-free period (Arrigo and van Dijken, 2011). However, the nutrient' balance dynamics might also be a controlling factor as the freshwater-driven enhancement of stratification comes to prevail over the nutrient supply from deep waters (Hansen et al. 2003). The mechanisms of the decrease of PP across the Greenland Sea sector (as we have mentioned above, which was also observed by Arrigo and van Dijken (2011)) over the time period 1998-2010 are not evident, and need a specifically focused study.

Concluding, we would like to emphasize that a continuation of this study is needed to perform a full validation of the different steps of the PP algorithms, to quantify when and why the algorithms may be failing. Also, the results reported here relate to a rather short time period. It needs to be significantly extended in order to draw solidly justified conclusions about the ongoing alterations of the Arctic Ocean's ecosystem.

What is necessary is a much richer database of gridded in situ measurements of PP (certainly including vertical profiles) over the immense tracts of the Arctic Ocean. This will allow one, among other things, to improve/develop new PP algorithms. Some extended and truly representative studies are required to elucidate the actual balance between PP in conditions of 
increasing the extent of open area and duration on the one hand, and the availability of nutrients on the other.

This implies that more knowledge is required on key processes determining the Arctic Ocean's ecosystem functioning, including trophic interactions, especially, at the fishzooplankton-phytoplankton levels. Special attention should be also given to the issue of the quantification of PP related to the ice habitats in conditions of their drastic reduction.

This is a rather short and certainly far from complete list of investigations promising to provide a more adequate vision of the changes in the Arctic ecosystem. Understandably, such investigations must be inseparably associated with/accompanied by hydrographic and climatological studies.

All this requires launching large-scale comprehensive national and international programmes dedicated to the Arctic Ocean with protocols encompassing simultaneous measurements of the variables mentioned above explicitly as well as implicitly.

\section{ACKNOWLEDGEMENTS}

This research was performed under the FP7 Programme (grant 'MONARCH-A FP7-SPA.2009.1.1.02'). We thank Drs Stephane Maritorena (Earth Research Institute, University of California, Santa Barbara, USA) and Robert O'Malley (Department of Botany and Plant Pathology, Oregon State University) for consulting us on the procedure of cloud flagging developed under the MEASURE Project, as well as personalities and institutions who provided us with in situ data.

\section{REFERENCES}

Arrigo, K., and van Dijken, G., 2008. Changes in Arctic Ocean Primary Production from 1998-2008. http://www.arcticnet.ulaval.ca/pdf/talks2008/arrigoKevin.pdf

Arrigo, K., and van Dijken, G., 2011. Secular Trends in Arctic Ocean Net Primary Production. Journal of Geophysical Research, 116 (C09011), pp. 1-15.

Arrigo, K., van Diiken,G., and Pabi, S.,. 2008. Impact of a Shrinking Arctic Ice Cover on Marine Primary Production. Geophysical Research Letters, 35 (L19603), pp. 1-6.

Babin, M., and Bélanger, S., 2011. How Useful are Ocean Colour Data to Monitor Changes in Primary Production and Detect Regime Shifts in the Arctic Ocean. Paper presented at a conference in Arctic Tipping Points Conference, Tromso, Norway, January 23-28, http://www.arcticfrontiers.com/.

Balch, W., Gordon, H., and Bowler, B., 2005. Calcium Carbonate Measurements in the Surface Global Ocean Based on Moderate Resolution Imaging Spectroradiometer Data. Journal of Geophysical Research, 110, pp. C07001.

Siegel, and Shea, D., 2005. Carbon-Based Ocean Productivity and Phytoplankton Physiology from Space. Global Biogeochemical Cycles, 19 (GB1006), pp. 1-14.

Behrenfeld, M., and Falkowski, P., 1997. Photosynthetic Rates Derived from Satellite-Based Chlorophyll Concentration. Limnology and Oceanography, 42(1), pp. 1-20.

Bukata, R., Jerome, J., Kondratyev, K., Pozdnyakov, D. 1995. Optical Properties and Remote Sensing of Inland and Coastal Waters, CRC Press, Boca Raton, pp. 145-149.
Greene, C., and Pershoin, A., 2007. Climate Drives Sea Change. Science, 315 (5815), pp. 1084-1085.

Hansen, A., Nielasen, T., Levinsen, H., Madsen, S., Thingstad, T., and Hansen, B., 2003. Impact of Changing Ice Cover on Pelagic Productivity and Food Web Structure in Disco Bay, West Greenland: A Dynamic Model Approach. Deep-Sea Research, Part I, 50, pp. 171-187.

Hessen, D.,.Carroll J. -L., Kjeldstad, B.,. Korosov, A., Pettersson., L., Pozdnyakov, D., Sørensen, K., 2010. Input of Organic Carbon as Determinant of Nutrient Fluxes, Light Climate and Productivity in the $\mathrm{Ob}$ and Yenisey Estuaries. Estuarine, Coastal and Shelf Science, 88 (1), pp. 53-62.

Kondratyev, K., Pozdnyakov, D., and Isakov, V., 1990. Radiation and Hydrooptical Experiments on Lakes. Nauka Press, Leningrad.

Korosov, A., Morozov, E., Pozdnyakov, D., Pettersson,L., and Grassl, H., 2009b. Spaceborne Identification and Mapping of the Areas of Coccolithophore Blooms in the Bay of Biscay. Earth Observations and Remote Sensing, 3, pp. 1-12.

Korosov, A. Pozdnyakov, D., Folkestad, A., Pettersson, H., Sorensen, K., and Shuchman, R. 2009a. Semi-Empirical Algorithm for the Retrieval of Ecology-Relevant Water Constituents in Various Aquatic Environments. Algorithms, 2, pp. 470-497.

Korosov, A., Pozdnyakov, D., and Grassl, H., 2011. Spaceborne Quantitative Assessment of Dissolved Organic Carbon Fluxes in the Kara Sea. Advances in Space Research. doi:10.1016/j.asr.2011.10.008

Maritorena, S., Siegel, D., and Peterson, A,. 2002. "Optimization of a Semi-Analytical Ocean Colour Model for Global-Scale Applications. Applied Optics, 41(15), pp. 27052714 .

Marra, J., Ho, C., and Trees, C,. 2003. LDEO Technical Report, \# LDEO-2003-1, National Aeronautics and Space Administration. An Alternative Algorithm for the Calculation of Primary Productivity from Remote Sensing Data Publication, 27, pp.56-86.

Morozov, E., Korosov,A., D. Pozdnyakov, D., Pettersson, L., and Sychev, V., 2010. A New Area-Specific Bio-Optical Algorithm for the Bay of Biscay and Assessment of its Potential for SeaWiFS and MODIS/Aqua Data Merging. Intrernational Journal of Remote Sensing, 31(24), pp. 6541-6565.

Morozov, E., Pozdnyakov, D., Smyth, T., Sychev, V., and Grassl, H., 2012. Spaceborne Study of Seasonal, Multi-Year and Decadal Phytoplankton Dynamics in the Bay of Biscay. International Journal of Remote Sensing, 34(4), pp. 1297-1331.

Pabi, S., van Dijken, G., and Arrigo, K., 2008. Primary Production in the Arctic Ocean, 1998-2006. Journal of Geophysical Research, 113 (C08005), pp. 1-22.

Peterson, B., Holmes R., McClelland, J., Vorosmarty C Lammers, R., Shiklomanov, A., Shiklomanov, I., and Rahmstor, S., 2002. Increasing River Discharge to the Arctic Ocean. Science, 298, pp. 2171-2173. 
Petrenko, D., Pozdnyakov, D., Johannessen, J., Counillion, F., and Sychov, V., 2013. Satellite derived primary production in the Arctic Ocean. International Journal of Remote Sensing, 34(11), pp. 3903-3937.

Press, W., Teukolsky, S., Vettering, W., and Flannery, B., 1992. Numerical Recipes in C: The Art of Scientific Computing. 2nd ed. Cambridge University Press, New York.

Robinson, I. S. 2004. Measuring the Oceans from Space: The Principles and Methods of Satellite Oceanography. Springer Praxis Books/Geophysical Sciences, Chichester, pp. 194-246.

Sathyendranath, S. 2000. General Introduction. In: Remote Sensing of Ocean Colour in Coastal, and Other OpticallyComplex, Waters, edited by S. Sathyendranath, 5-21. IOCCG Report No. 3. IOCCG Publishing, Darthmouth.

Schmid, M., Piepenburg, D., Golikov, A.,. von Juterzenka, K, Pestryakov, V., and Spindler, M., 2006. Trophic Pathways and Carbon Flux Patterns in the Laptev Sea. Progress in Oceanology 71(2-4), pp. 314-330.

Timmermans, M., Proshutinsky, A., Krishfield, R., Perovich, D., Richter-Menge, J., Stanton, T., and Toole, J., 2011. Surface Freshening in the Arctic Ocean's Eurasian Basin: An Apparent Consequence of Recent Change in the Wind Driven Circulation. Journal of Geophysical Research, 116 (C00D03), pp. 1-17. 